\title{
Stimulus Equivalencies Through Discrimination Reversals
}

\section{Juan D. Delius, Masako Jitsumori, and Martina Siemann}

The sensory systems of advanced animals frequently input more stimulus information into the nervous system than the motor system can possibly output as behavior patterns. This bottleneck demands a drastic information reduction. Two types of reduction can be distinguished: selective attention involving behavioral contextdependent information censoring (as when during sexual behavior food stimuli are usually not reacted to); and categorization, a pooling into fewer response outputs (as when different foods all elicit the same ingestive response). Here we are concerned with processes underlying this latter kind of information reduction, that is, how the nervous system manages to classify stimuli so that they result in a restricted number of behaviors.

In human psychology, such information pooling has been much studied under the heading of concept formation, where the responses of interest have been words, which through suitable experience, come to correspond semantically to collections of stimuli (Sloman and Rips, 1998). There are several theories about the formation of concepts but no single one has emerged as being uniquely correct (Fodor, 1998). The deviousness of the human mind at conceiving named categories exceeds any succinct hypothesis that can be put to paper. Consider the terms male and female as applied to organisms from algae to humans and to objects such as the sun and the moon. "Le soleil" and "la lune," "die Sonne" and "der Mond" are conversely male and female to franco- and germanophone people. Most theories assume that the stimuli that come to be categorized together do so on the basis of perceptual similarities, either by simply being neighbors along a physical dimension such as size or wavelength, or by sharing some physical features such as feathers or legs. The contribution of less immediate similarities of stimuli or items, such as the ability to fly or to kill, or whatever confers genders to the sun and the moon, have also been considered theoretically but have hardly been examined empirically. A stimulus categorization by these kind of functional attributes interests us here, though not so much in humans as in pigeons.

The ability of pigeons to learn to distinguish sets of stimuli that are physically similar within sets and physically different between sets (for example, slides containing humans or not containing humans) in a directly perceivable way as belonging to different categories (as being worth or not worth pecking for food returns, for example), and the competence to then spontaneously generalize this discrimination to novel but still correspondingly similar and different stimuli without additional training, was first established by Herrnstein and Loveland in 1964. Analogous results have since been replicated with a wide variety of stimuli (e.g., Lubow, 1974; Delius, 1992). Pigeons have proven not only capable of categorizing pictures of natural objects but 
also able to categorize artificial scenes such as impressionist and cubist paintings (Watanabe et al., 1995). Moreover, Bhatt et al. (1988) showed that they could not only classify pictures dichotomously but that they also could concurrently categorize pictures of four classes of objects. Kirpatrick-Steger and Wasserman (1996) had no particular difficulty in having pigeons categorize stimuli according to whether one of two shapes was above, below, to the left, or to the right of the other. The limits might lie in the abstractness of the properties that make the stimuli in an intended category similar. Herrnstein et al. (1989) found it difficult to train pigeons to categorize drawings of dots within closed curved lines from drawings of dots outside such lines. These limits aside, for a long time the remarkable categorization performances of pigeons were equated with an ability to conceptualize, following a definition by Keller and Schoenfeld (1950) affirming that concepts involved a generalization within classes and a discrimination between classes of stimuli.

\section{Concepts Through Reversals}

Lea (1984) argues that the term concept should be used only if the stimuli pertaining to a category are shown to be associated with each other and not only with a response or a reinforcement. He proposes that such inter-stimulus association can be demonstrated by retraining the animals with a subset of the category stimuli (or the features composing them) with reversed reinforcement allocations and then testing for whether the reversed response would spontaneously transfer to the remaining stimuli (features). If all stimuli (features) belonging to a category were bonded by associations, the response switch should transfer from the leading subset to the trailing subset.

The procedure yielded mixed results. Lea et al. (1990) had pigeons discriminate sets of letters, and upon a single reversal they found some evidence of reversal transfer. Fersen and Lea (1990) trained pigeons to discriminate two sets of townscapes involving several features. When reversed with respect to one pair of features they showed no evidence of transfer to the other features. Bhatt and Wasserman (1989) had pigeons categorize pictures of four different types of objects, but found that reversal training did not transfer. Jitsumori (1993) got pigeons to successfully categorize artificial multifeatured stimuli according to feature addition principles but found no reversal transfer across features. Astley and Wasserman (1998) had pigeons learn to co-categorize pictures of people, flowers, cars, and chairs into two classes and similarly found only rather weak evidence of inter-stimulus associations using a response reassignment procedure. All these studies exposed the animals to only a 
single reversal or reassignment before testing for choice transfer. They were thus expecting that inter-stimulus associations would have arisen through the earlier categorization training rather than by the reassignment or reversal procedure itself.

Vaughan (1988) used the reversal method for both strengthening the inter-stimulus associations and testing them. Pigeons learned to discriminate slides all depicting trees but which were arbitrarily divided into a set of 20 positive and a set of 20 negative slides. The slides were projected in a random order onto a pecking key. Only pecks on the positive pictures yielded food rewards. When the pigeons had learned to discriminate, the allocation of reward and no reward was exchanged between the sets. Such reinforcement reversals were repeated until the birds became proficient at switching their choices according to the reigning allocations. Vaughan then showed that upon a reversal, experience with a few initial slides was sufficient to cause the pigeons to respond correctly to all the remaining ones. That is, when the pigeons detected that some of the slides of the sets had exchanged their functional significance, they spontaneously transferred the adequate response to the remainder.

This led Herrnstein (1990) to expand his views about conceptualization in animals. To the previously accepted levels of (a) stimulus categorization based on straightforward discrimination, (b) on brute, multiple by-rote learning, (c) on open-ended extension through generalization gradients, and (d) on common abstract relations between stimulus components, he added a new level (e) where the categorization of stimuli was not based on perceptual similarities between them but based on reinforcement contingencies that different stimuli could share. This latter level corresponded to the stimulus classification by multiple reinforcement reversals demonstrated by Vaughan (1988). Note, however, that there is nothing to prevent the processes responsible for the different levels of categorization from operating conjointly.

\section{Equivalencies by Matching}

Vaughan (1988) maintained that his pigeons had formed two equivalence sets in the sense that experience with any exemplar of each class was equally capable of eliciting a choice switch. This view conflicted with another research tradition developed by Sidman (1992) and others (Dougher and Markham, 1996). Employing the so-called symbolic matching-to-sample conditioning procedure, Sidman began by attempting to teach verbally backward humans the correspondence among pictograms of items such as a car, a bed, an ear, and so on with the written words "car," "bed," "ear," and so forth. Later he used purely arbitrary, initially meaningless stimuli. Although Sidman himself did little animal work on this (Sidman et al., 1982), his designs lend themselves to such an enterprise. 
Table 6.1

Minimal equivalencies design employing a symbolic matching-to-sample procedure

\begin{tabular}{|c|c|c|c|}
\hline \multicolumn{2}{|l|}{ 1. Matching training } & \multicolumn{2}{|l|}{ 2. Reflexivity testing } \\
\hline$-\mathrm{LA} B+$ & $\mathrm{A} \equiv \mathrm{B}$ & oK A Ao & $\mathrm{A} \equiv \mathrm{A} ?$ \\
\hline +B A L- & $\mathrm{A} \equiv \mathrm{B}$ & oA A Ko & $\mathrm{A} \equiv \mathrm{A} ?$ \\
\hline$-\mathrm{M} \mathrm{B} \mathrm{C}+$ & $\mathrm{B} \equiv \mathrm{C}$ & oL B Bo & $\mathrm{B} \equiv \mathrm{B} ?$ \\
\hline$+\mathrm{C} \mathrm{B} \mathrm{M-}$ & $\mathrm{B} \equiv \mathrm{C}$ & oB B Lo & $\mathrm{B} \equiv \mathrm{B} ?$ \\
\hline$-\mathrm{B} \mathrm{KL}+$ & $\mathrm{K} \equiv \mathrm{L}$ & oK K Ao & $\mathrm{K} \equiv \mathrm{K} ?$ \\
\hline$+\mathrm{L} \mathrm{K} \mathrm{B-}$ & $\mathrm{K} \equiv \mathrm{L}$ & etc. ... & \\
\hline$-\mathrm{C} \mathrm{L} \mathrm{M+}$ & $\mathrm{L} \equiv \mathrm{M}$ & & \\
\hline$+\mathrm{M} \mathrm{L} \mathrm{C}-$ & $\mathrm{L} \equiv \mathrm{M}$ & & \\
\hline 3. Symmetry testing & & 4. Transitivity testing & \\
\hline oK B Ao & $\mathrm{B} \equiv \mathrm{A} ?$ & oM A Co & $\mathrm{A} \equiv \mathrm{C} ?$ \\
\hline oA B Ko & $B \equiv A ?$ & oC A Mo & $\mathrm{A} \equiv \mathrm{C} ?$ \\
\hline oL C Bo & $\mathrm{C} \equiv \mathrm{B} ?$ & oC K Mo & $\mathrm{K} \equiv \mathrm{M} ?$ \\
\hline oB C Lo & $\mathrm{C} \equiv \mathrm{B} ?$ & oM K Co & $\mathrm{K} \equiv \mathrm{M} ?$ \\
\hline etc. ... & & etc. ... & \\
\hline
\end{tabular}

The sample stimuli are presented on a middle pecking key and the comparison stimuli are presented on two side keys. There are six different stimuli A, B, C and K, L, M. The symbols +, -, and o stand for reward, penalty, and nonreinforcement, respectively (modified from Sidman, 1992 by the inclusion of unreinforced test trials).

Adapted for pigeons, the procedure could run as follows: On a given trial stimulus A, say pattern \# might be shown on the middle key; when pecked it would switch on stimulus B, say pattern $\S$ on one side-key and stimulus K, say pattern @ on the other side-key. The comparison stimulus B is defined as matching the sample stimulus A, and if the pigeon pecks it, it is rewarded. If it pecks the comparison stimulus $\mathrm{L}$, defined as not matching the sample stimulus $\mathrm{A}$, it is penalized. This teaches the birds to match the sample stimulus A by choosing the stimulus B and thus to possibly learn the equivalence relation $\mathrm{A} \equiv \mathrm{B}$. Table 6.1 sketches a design attempting to teach pigeons the equivalence relations $\mathrm{A} \equiv \mathrm{B}, \mathrm{B} \equiv \mathrm{C}$ and $\mathrm{K} \equiv \mathrm{L}, \mathrm{L} \equiv \mathrm{M}$, each letter standing for a different stimulus. Part 2 delineates tests for reflexivity, that is, for whether the same stimuli serving both as a sample and a comparison are recognized as equivalent. Part 3 sketches tests for symmetry, that is, whether when the stimuli that previously served as samples are now used as comparison stimuli, and conversely are still recognized as equivalent. Part 4 sketches tests for transitivity, whether pigeons can derive from the previously learned equivalencies the emergent equivalencies $\mathrm{A} \equiv \mathrm{C}$ and $\mathrm{K} \equiv \mathrm{M}$. Only when pigeons pass all these tests would they command what Sidman calls the equivalence classes $\{\mathrm{A}, \mathrm{B}, \mathrm{C}\}$ and $\{\mathrm{K}, \mathrm{L}, \mathrm{M}\}$. If the pigeons learned part 1 on the basis of a configural rather than a relational strategy, they would of course not pass them. 
Language competent humans pass the tests without much difficulty, but language deficient subjects tend to fail on one or another test and only master the corresponding stages after remedial reinforced training with them. Normal children begin to fully command equivalence classes when they are linguistically competent, at the age of about six years (Sidman, 1992). Younger children tend to have difficulties with the symmetry and transitivity tests (Valero-Aguayo and Luciano-Soriano, 1996). While nonhuman primates have managed to pass some of the Sidman criteria (D'Amato et al., 1985; Yamamoto and Asano, 1995), pigeons have mostly proven incapable of passing any of them (Lipkens et al., 1988; Jitsumori, 1990; Fersen et al., 1992). Only Kuno et al. (1994), using a design bypassing the reflexivity and symmetry hurdle, got one of four pigeons to pass the transitivity test. Zentall and Urciuoli (1994) argue that pigeons variously passed the reflexivity, symmetry, and transitivity tests, but their evidence is pieced together from a methodically heterogeneous collection of experiments.

The fact that Vaughan (1988) used a different paradigm and did not test for reflexivity, symmetry, and transitivity caused Sidman to be initially critical of his equivalence class demonstration. However, when he found out that human subjects benefited from a multiple reversal pretraining with regards to passing these tests, he relaxed his views somewhat (Sidman et al., 1989; Sidman, 1992).

\section{Reversals Continued}

All studies using the reversal technique with pigeons, whether successful or not, employed many and/or complex stimuli. Because this hampers the analysis of equivalence class formation, Delius et al. (1995) ran an experiment employing only four simple stimuli. Using a simultaneous two-key conditioning procedure, pigeons were taught to concurrently discriminate the colors red/green and blue/yellow according to the scheme $\mathrm{A}+\mathrm{K}-, \mathrm{B}+\mathrm{L}-$, where the + and - signs mean that pecks were rewarded with food or were penalized with time-out. When the birds had learned this task, the reinforcement allocations were reversed to $\mathrm{A}-\mathrm{K}+, \mathrm{B}-\mathrm{L}+$, and when they had learned this they were again reversed to $\mathrm{A}+\mathrm{K}-, \mathrm{B}+\mathrm{L}-$ (table 6.2 [1]). The reversal procedure was repeated about 35 times, until the birds became proficient in switching their stimulus choices. This was to ensure that the birds learned that the A, B and $\mathrm{K}$, L stimuli were consistently yoked together. Subsequent tests for the equivalencies $\mathrm{A} \equiv \mathrm{B}$ and $\mathrm{K} \equiv \mathrm{L}$ involved special reversal sessions where only one of the two discrimination pairs was presented during the first ten or so trials. These leading trials gave the birds time enough to adopt an at least 85 percent correct responding. During the remainder of the session the other, trailing discrimination pair was additionally presented. The first two trials with this trailing pair went unreinforced. The pigeons 
Table 6.2

Basic design of multiple reversal equivalence training and testing, typical sequences of simultaneous discrimination trials

\begin{tabular}{llll}
\hline 1. Equivalencies training $\mathrm{A} / \mathrm{K} \equiv \mathrm{B} / \mathrm{L}$ & & \\
& reversal & reversal & reversal \\
discrimination & $\mathrm{A}+A-B-B-A-B-\ldots$ & $A-\mathrm{B}+\mathrm{B}+\mathrm{A}+\ldots$ & $B-\ldots$ \\
$\mathrm{A}+\mathrm{B}+\mathrm{B}+\mathrm{B}+\mathrm{A}+\mathrm{A}+\mathrm{B}+\ldots$ & $\mathrm{K}-K+L+L+K+L+\ldots$ & $K+\mathrm{L}-\mathrm{L}-\mathrm{K} \ldots$ & $L+\ldots$
\end{tabular}

2. Reversal test for $\mathrm{A} / \mathrm{K} \equiv \mathrm{B} / \mathrm{L}$ ? and $\mathrm{B} / \mathrm{L} \equiv \mathrm{A} / \mathrm{K}$ ?

$\begin{array}{llll}\text { leading } & \text { trailing } & \text { leading } & \text { trailing } \\ \mathrm{A}+\mathrm{A}+\mathrm{A}+\mathrm{A}+\ldots & \mathrm{A}+\mathrm{Bo} \mathrm{A}+\mathrm{Bo} \mathrm{A}+\mathrm{B}+\ldots & \mathrm{A}+B-B-B-\ldots & B-A o \text { Ao } A-B-\ldots \\ \mathrm{K}-\mathrm{K}-\mathrm{K}-\mathrm{K}-\ldots & \mathrm{K}-\mathrm{Lo} \mathrm{K}-\mathrm{Lo} \mathrm{K}-\mathrm{L}-\ldots & \mathrm{K}-L+L+L+\ldots & L+K o \text { Ko K}+L+\ldots\end{array}$

3. Full and half reversal tests for $\mathrm{A} / \mathrm{K} \equiv \mathrm{B} / \mathrm{L}$ ?

full reversal

$B-B-A-B-A-\mathrm{B}+\mathrm{B}+\mathrm{A}+\mathrm{A}+\ldots$

$L+L+K+L+K+\mathrm{L}-\mathrm{L}-\mathrm{K}-\mathrm{K}-\ldots$

The stimuli forming the discriminatory pairs are shown one above the other. Reinforcement allocation reversals are marked by switches from standard to italic font and back. The symbols,+- , and o stand for reward, penalty, and nonreinforcement. For simplicity the randomized left-right position of the stimuli is not represented (after Delius et al. 1995).

showed 37 percent correct initial trials with the leading pair and 48 percent correct initial trials with the trailing pair trials. In accordance with the equivalence hypothesis, the reversal experience with the leading pair facilitated the choice switch with respect to the trailing pair. After the pigeons were additionally trained with reversals incorporating some trials with half-key red/half-key blue (A|B) and half-key green/ half-key yellow $(\mathrm{K} \mid \mathrm{L})$ stimulus pairs meant to strengthen the associations through spatial contiguity, renewed tests yielded a more clearly significant 39 percent correct leading and 49 percent correct trailing pair difference.

However, the test results could also have arisen if the birds had adopted a nondiscriminative, 50 percent correct responding toward the initial trailing pair presentations after noticing the leading pair reversal. An additional test session series using a design by Nakagawa (1992) and not open to this option was thus run (table 6.2 [3]). Half of the sessions implemented full reversals affecting both pairs in a like manner. They alternated with sessions involving half reversals where one discrimination pair was subject to a reinforcement reversal but the other was not. Because these half reversals were at odds with the equivalencies presumably induced by the full training reversals, it was expected the birds would not adjust as well to them as to the full reversals. This happened: the pigeons showed an average 63 percent and 70 percent correct choices during the first ten trials of these two types of sessions. This 

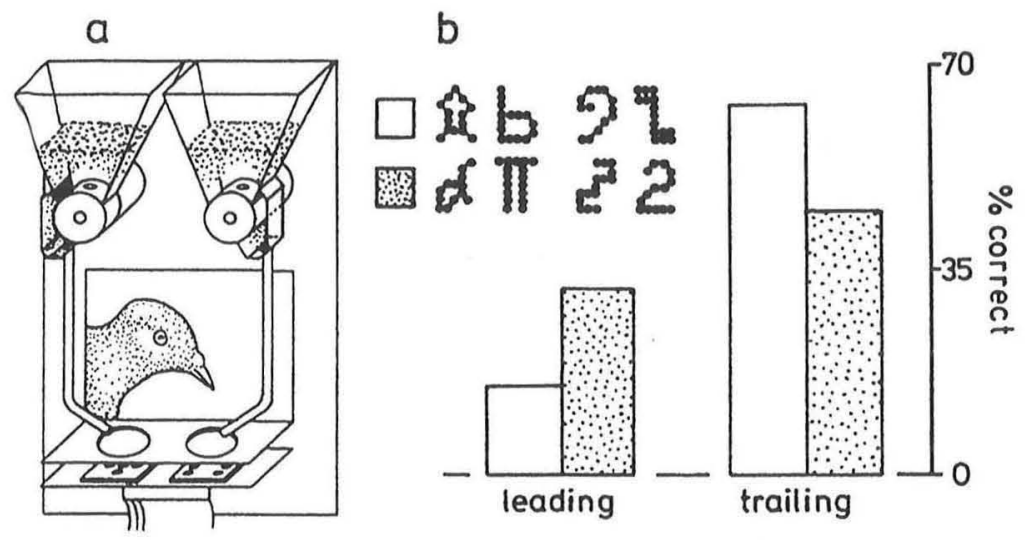

Figure 6.1

(a) conditioning platform used for the Siemann and Delius (1998a), Siemann (1998), and Jitsumori et al. (1999) studies (from Xia et al. 1996); (b) stimuli employed and average performance during the initial trials with the leading and trailing pairs during the test reversal in the Siemann and Delius (1998a; clear) and the Siemann (1998; stippled) studies.

significant difference contradicted the simpler expectancy that a relearning of two reversed pairs discrimination would be more difficult than the relearning of a single reversed pair discrimination. The result thus rather supports the notion that the color stimuli had become partly equivalent in an $\mathrm{A} \equiv \mathrm{B}, \mathrm{K} \equiv \mathrm{L}$ manner. Comparable results were obtained in a similar half and full reversal experiment carried out by Zentall et al. (1991).

Because red is next to yellow and green is next to blue on the wavelength spectrum, it seemed possible that stimulus generalization could have worked against the intended red $\equiv$ blue and yellow $\equiv$ green equivalencies. Siemann and Delius (1998a) therefore conducted a multiple reversal experiment using shapes. Pigeons were conditioned using platforms attached to the cages. The stimuli were light diode array patterns presented below the two transparent keys. Feeders delivered a few grains of millet onto either key (figure 6.1a). Shapes chosen to be physically dissimilar formed the pairs $\mathrm{A}+-\mathrm{K}-+$ and $\mathrm{B}+-\mathrm{L}-+$, the symbol combinations +- and -+ indicating the repeated and synchronous reinforcement reversals they were subjected to. These came into effect whenever the pigeons had reached a criterion performance of 70 percent correct choices within a 40-trial block. Test blocks were introduced when the number of trials that the birds needed to reach this criterion roughly stabilized after some 100 reversals. There were 20 blocks of about 120 trials structured according to the leading/trailing design explained earlier. Only when the leading pair had been presented some 20 times in a row was the trailing pair presented as well.

All three pigeons yielded a better performance during the initial trials with the trailing pair than during the initial trial with the leading pair. The conditional 
extinction process considered earlier is unlikely to have applied because they yielded a better than 50 percent chance performance with the trailing pair. The mean scores were 63 percent and 17 percent, respectively (figure 6.1b). The large difference between the scores indicates a sizeable reversal transfer across the discrimination pairs and thus a marked $\mathrm{A} / \mathrm{K} \equiv \mathrm{B} / \mathrm{L}$ equivalencies command. Siemann (1998) ran a repeat experiment with a similar procedure but employing different stimuli (figure $6.1 \mathrm{~b}$ ). The three new pigeons again yielded a performance advantage with the trailing pair over the leading pair, the mean scores being 45 percent and 32 percent correct (figure $6.1 \mathrm{~b}$ ). The lesser difference between the scores could be due to the fact that one of the stimulus pairs consisted of two somewhat similar shapes.

Although supporting the equivalence formation through multiple reversals, our studies could not reproduce the large reversal transfer effect obtained by Vaughan (1988). Apart from some procedural differences of doubtful relevance, there is the fact that we employed a few simple stimuli selected to be dissimilar within each of the stimulus sets, whereas Vaughan employed many complex but generally similar stimuli within each of the stimulus sets. There is evidence that similarity and the number of stimuli used for training play a role in the establishment of relational principles in pigeons (Wright et al., 1988; Delius, 1994). This is undoubtedly because the similarity factor allows the grouping process to grow upon already present stimulus generalization links and because the number factor helps to overload the nonrelational, rote learning option to which pigeons are otherwise prone (Vaughan and Greene, 1984; Fersen and Delius, 1989).

\section{Equivalencies by Reversals}

Jitsumori et al. (2000) employed more stimuli of a controlled similarity, as well as an improved multiple reversal procedure. Five pigeons made up the similarity group about which we mainly report here. Two sets of four light diode stimuli served to begin with (figure 6.2a,b). Human observers judged them to be similar within sets and to be dissimilar between sets. The allocation of the different patterns within the A, B, $\mathrm{C}, \mathrm{D}$ and $\mathrm{K}, \mathrm{L}, \mathrm{M}, \mathrm{N}$ sets of stimuli was randomized across the birds.

The pigeons were first taught the twin equivalencies $\mathrm{A} \equiv \mathrm{B}$ and $\mathrm{K} \equiv \mathrm{L}$ (abbreviated: $\mathrm{A} / \mathrm{K} \equiv \mathrm{B} / \mathrm{L}$ ) with the stimulus pairs $\mathrm{A}+\mathrm{K}-, \mathrm{A}+\mathrm{L}-, \mathrm{B}+\mathrm{L}-, \mathrm{B}+\mathrm{K}-$ presented in random order (table 6.3 [1]). The training continued until the birds consistently achieved a better than 80 percent correct performance. The reinforcement allocation to the discrimination pairs was then reversed to $A-K+, A-L+$, $B-L+, B-K+$. Training continued until the above criterion was reattained. Rein- 


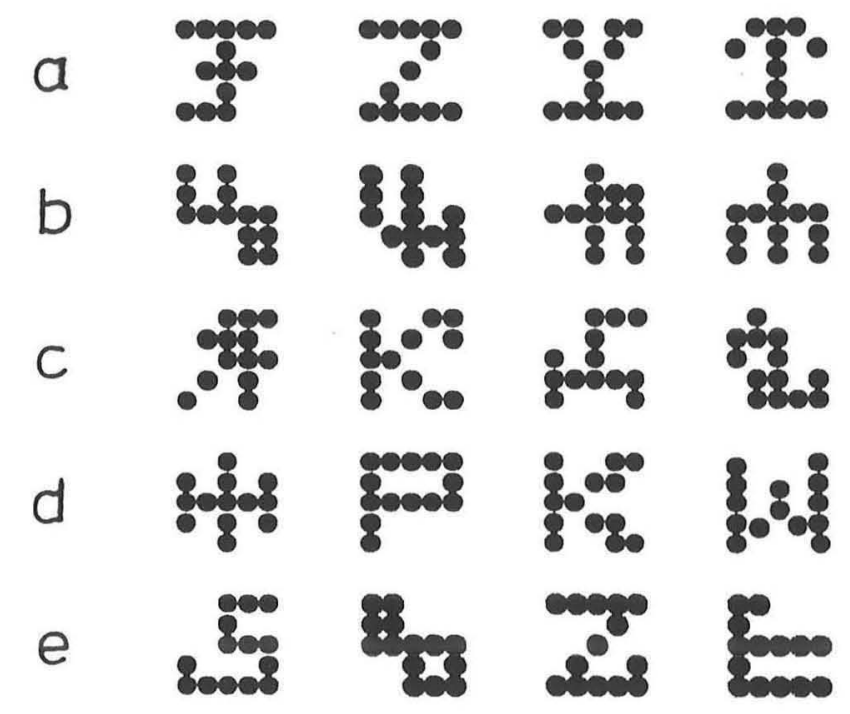

Figure 6.2

Light diode stimuli used by Jitsumori et al. (2000). The similarity group of pigeons first dealt with the patterns shown in the rows $\mathrm{a}$ and $\mathrm{b}$ and later additionally with those shown in row $\mathrm{c}$. The dissimilarity group to be mentioned later dealt with the patterns shown in rows $\mathrm{d}$ and $\mathrm{e}$.

forcements were then reversed again, and so on until the birds exhibited more than 80 percent correct within the first blocks after a reversal during three successive reversals. Then the pigeons where taught the equivalencies $\mathrm{C} / \mathrm{M} \equiv \mathrm{D} / \mathrm{N}$ using the same procedure with the discrimination pairs $\mathrm{C}+-\mathrm{M}-+, \mathrm{C}+-\mathrm{N}-+, \mathrm{D}+-\mathrm{M}-+$, $\mathrm{D}+-\mathrm{N}-+$, where the symbols +- and -+ indicate the multiple reversals they were subjected to (table 6.3 [1]). The birds achieved the criterion on both tasks within 30 70 reversals.

To test whether the equivalencies $\mathrm{A} / \mathrm{K} \equiv \mathrm{B} / \mathrm{L}, \mathrm{D} / \mathrm{N} \equiv \mathrm{C} / \mathrm{M}$ had been formed we examined whether a reinforcement reversal affecting the stimuli $\mathrm{A}, \mathrm{K}$ and $\mathrm{D}, \mathrm{N}$ would transfer to the stimuli $\mathrm{B}, \mathrm{L}$ and $\mathrm{C}, \mathrm{M}$, and the converse. Test sessions began with reinforced presentations of one set of stimulus pairs, the leading pairs, until the usual criterion was reached. A test block followed. It consisted of further training trials with the leading pairs and randomly interspersed, unreinforced probe trials with the other set of pairs, the trailing pairs. A second test session proceeded identically, except that the reinforcements of the leading pairs were reversed (table 6.3b). One test session dyad involved the leading pairs $\mathrm{A}+-\mathrm{K}-+, \mathrm{D}+-\mathrm{N}-+, \mathrm{A}+-\mathrm{N}+-$, $\mathrm{D}+-\mathrm{K}+-$, and the trailing pairs BoLo, CoMo, BoMo, CoLo. The other dyad involved the leading pairs $\mathrm{B}+-\mathrm{L}-+, \mathrm{C}+-\mathrm{M}-+, \mathrm{B}+-\mathrm{M}-+, \mathrm{C}+-\mathrm{L}-+$ and the trailing pairs AoKo, DoNo, AoNo, DoKo. The session pairs were arranged so that when the average test score across them was over 50 percent correct this indicated a 


\section{Table 6.3}

Sketch of the basic experimental design

1. Equivalencies training $\mathrm{A} / \mathrm{K} \equiv \mathrm{B} / \mathrm{L}$ and $\mathrm{C} / \mathrm{M} \equiv \mathrm{D} / \mathrm{N}$ training reversal

$\mathrm{A}+\mathrm{A}+\mathrm{B}+\mathrm{A}+\mathrm{B}+\ldots \mathrm{A}+\mathrm{A}+\mathrm{B}+B-A-A-B-\ldots A-B-B-$

$\mathrm{K}-\mathrm{L}-\mathrm{K}-\mathrm{K}-\mathrm{L}-\ldots \mathrm{L}-\mathrm{K}-\mathrm{L}-\mathrm{L}+K+K+K+\ldots K+L+L+$

training

reversal

$\mathrm{C}+\mathrm{D}+\mathrm{D}+\mathrm{D}+\mathrm{C}+\ldots \mathrm{C}+\mathrm{D}+\mathrm{D}-\mathrm{D}-\mathrm{C}-\mathrm{C}-\ldots$

$\mathrm{N}-\mathrm{M}-\mathrm{N}-\mathrm{N}-\mathrm{M}-\ldots \mathrm{M}-\mathrm{N}-\mathrm{M}+\mathrm{M}+\mathrm{N}+\mathrm{M}-\ldots$

2. Equivalencies testing $\mathrm{A} / \mathrm{K} \equiv \mathrm{B} / \mathrm{L}$ ? and $\mathrm{C} / \mathrm{M}=\mathrm{D} / \mathrm{N}$ ?

training test test test

$\mathrm{A}+\mathrm{A}+\mathrm{D}+\mathrm{A}+\ldots \mathrm{A}+\mathrm{D}+\mathrm{B}$ o $\mathrm{A}+\mathrm{B}$ o $\mathrm{D}+\mathrm{D}+\mathrm{Co} \mathrm{A}+\mathrm{A}+\mathrm{D}+$

$\mathrm{K}-\mathrm{K}-\mathrm{N}-\mathrm{N}-\ldots \mathrm{N}-\mathrm{K}-\mathrm{Lo} \mathrm{K}-\mathrm{Mo} \mathrm{N}-\mathrm{K}-\mathrm{Lo} \mathrm{K}-\mathrm{K}-\mathrm{N}-$

test reversal test test test

Co ... B-B-C-B-... C-Ao Ao B-Do...

Mo ... $L+M+L+L+\ldots M+K o$ NoM+No ...

See table 6.2 and the text for further explanations (after Jitsumori et al., 2000). 

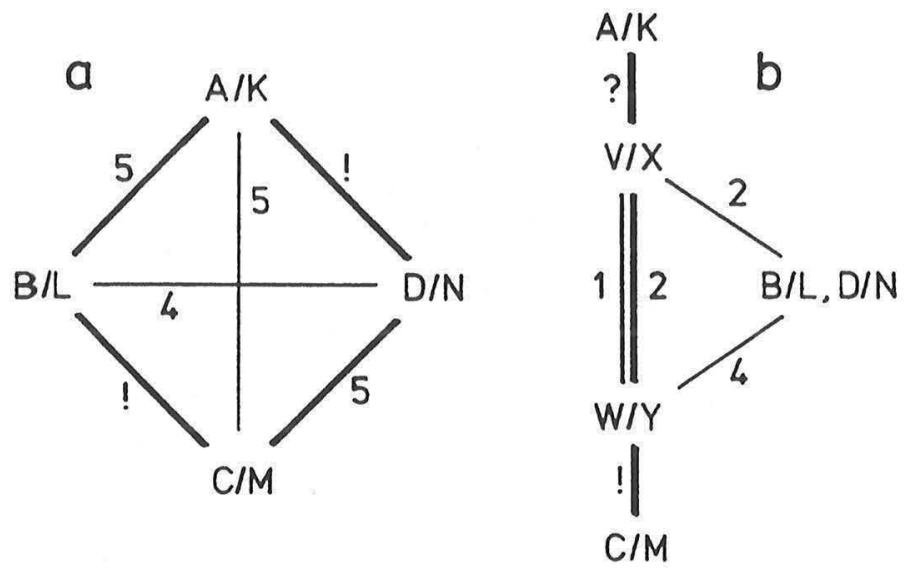

Figure 6.3

Equivalencies that were trained (thick lines) and equivalencies that could emerge by transitivity (thin lines). The equivalencies tested are flanked by the number of birds commanding them. Equivalencies inferred to have or not have been commanded by most birds are marked with ! and ? symbols; (a) before and (b) after the incorporation of dissimilar stimuli. (Modified from Jitsumori et al. 2000)

choice transfer from the leading pairs to the trailing pairs, an approximately 70 percent correct score signaling a significant transfer. The actual scores for all pairs and each bird exceeded that level by being between 78 percent and 100 percent correct, implying a command over the equivalencies $\mathrm{A} / \mathrm{K} \equiv \mathrm{B} / \mathrm{L}, \mathrm{D} / \mathrm{N} \equiv \mathrm{C} / \mathrm{M}$. Figure $6.3 \mathrm{a}$ summarizes these findings.

The pigeons were next taught the equivalencies $\mathrm{A} / \mathrm{K} \equiv \mathrm{D} / \mathrm{N}, \mathrm{B} / \mathrm{L} \equiv \mathrm{C} / \mathrm{M}$, using analogous procedures. Their command, however, was not directly tested. Instead, we tested whether the birds dominated the equivalencies $\mathrm{A} / \mathrm{K} \equiv \mathrm{C} / \mathrm{M}, \mathrm{B} / \mathrm{L} \equiv \mathrm{D} / \mathrm{N}$ that had not been explicitly trained but which the pigeons could in principle derive by transitivity if they had formed the equivalence classes $\{\mathrm{A}, \mathrm{B}, \mathrm{C}, \mathrm{D}\}$ and $\{\mathrm{K}, \mathrm{L}, \mathrm{M}, \mathrm{N}\}$ (figure 6.3a). The test sessions were structured as before but involved the leading training/trailing test pairs $\mathrm{A}+-\mathrm{K}-+/ \mathrm{CoMo}, \mathrm{C}+-\mathrm{M}-+/$ AoKo, $\mathrm{B}+-\mathrm{L}-+/ \mathrm{DoN}$, and $\mathrm{D}+-\mathrm{N}-+/ \mathrm{BoLo}$. The birds achieved significant above chance level performances of between 72 percent and 100 percent correct trials with the various test pairs, except that one bird that was weak on the DoNo pair. Figure 6.3a summarizes the results. The mastery of these $A / K \equiv C / M$ and $B / L \equiv D / N$ equivalencies by four birds indirectly demonstrated that they also commanded the equivalencies $\mathrm{A} / \mathrm{K} \equiv$ $\mathrm{D} / \mathrm{N}$ and $\mathrm{B} / \mathrm{L} \equiv \mathrm{C} / \mathrm{M}$. They had thus integrated the equivalencies into a network so that the stimuli were associatively clustered in two separate $\{\mathrm{A}, \mathrm{B}, \mathrm{C}, \mathrm{D}\}$ and $\{\mathrm{K}, \mathrm{L}, \mathrm{M}, \mathrm{N}\}$ classes. Within these classes each and all member stimuli were capable of signaling a reinforcement switch causing a response switch to the remaining members. 


\section{Dissimilarities Interfere}

The equivalence formation reflected by these results with similar-within and dissimilar-between stimuli is far better than that obtained during our earlier efforts using a similar procedure but with dissimilar within-class stimuli. Indeed, the results compare with those of Vaughan (1988) that also involve similar within-class stimuli. To further assess the role of stimulus similarity/dissimilarity, our pigeons were now confronted with additional equivalence tasks involving dissimilar stimuli. Four patterns that human observers judged dissimilar to one another and dissimilar to the patterns constituting the two earlier sets were constructed (figure 6.2c). The assignment of these patterns as $\mathrm{V}, \mathrm{W} \mathrm{X}, \mathrm{Y}$ stimuli was randomized across the birds that were trained to learn the equivalencies $\mathrm{A} / \mathrm{K} \equiv \mathrm{V} / \mathrm{X}$ and $\mathrm{C} / \mathrm{M} \equiv \mathrm{W} / \mathrm{Y}$ according to the same procedure employed before. Although the birds were now experienced with the discrimination reversal routine, they took longer to learn with these stimuli than with the earlier ones. The birds were then tested in the usual manner using the leading pairs $\mathrm{B}+-\mathrm{L}-+$ and $\mathrm{D}+-\mathrm{N}-+$ and the trailing pairs VoXo and WoYo. This tested them for the mastery of the equivalencies $\mathrm{B} / \mathrm{L} \equiv \mathrm{V} / \mathrm{X} \equiv \mathrm{D} / \mathrm{N}, \mathrm{B} / \mathrm{L} \equiv \mathrm{W} / \mathrm{Y} \equiv \mathrm{D} / \mathrm{N}$, which they had not been explicitly taught but that they could potentially derive. The test scores with the WoYo pair were all, except in one bird, significantly above chance, but with the VoXo pair they were only significant for two birds (figure 6.3b). It seems that some birds had learned the $\mathrm{A} / \mathrm{K} \equiv \mathrm{V} / \mathrm{X}$ less well than the $\mathrm{C} / \mathrm{M} \equiv \mathrm{W} / \mathrm{Y}$ equivalencies.

We then tested whether the birds had derived the untaught equivalencies $\mathrm{V} / \mathrm{X} \equiv$ $\mathrm{W} / \mathrm{Y}$ using the leading pairs/trailing pairs $\mathrm{V}+-\mathrm{X}-+/ \mathrm{WoYo}$ and $\mathrm{W}+-\mathrm{Y}-+/$ VoXo. The test scores were all close to chance except those of one bird that achieved significant scores. After a subsequent training of the $\mathrm{V} / \mathrm{X} \equiv \mathrm{W} / \mathrm{Y}$ equivalencies, a repeat of the same test revealed some asymmetry in the sense that although two birds scored significantly in both tests, two birds were successful only with the WoYo test pair, and one bird failed on both tests. The asymmetry was probably due to the fact that most pigeons had earlier learned the equivalencies $\mathrm{C} / \mathrm{M} \equiv \mathrm{W} / \mathrm{Y}$ but not learned the equivalencies $\mathrm{A} / \mathrm{K} \equiv \mathrm{V} / \mathrm{X}$ (figure 6.3b). Thus four pigeons of Jitsumori et al.'s (1999) so-called similarity group ended up incorporating dissimilar stimuli into the equivalence classes $\{\mathrm{A}, \mathrm{B}, \mathrm{C}, \mathrm{D}, \mathrm{W}\},\{\mathrm{K}, \mathrm{L}, \mathrm{M}, \mathrm{N}, \mathrm{Y}\}$, and one forming the probably disjoint classes $\{\mathrm{A}, \mathrm{B}, \mathrm{C}, \mathrm{D}\},\{\mathrm{K}, \mathrm{L}, \mathrm{M}, \mathrm{N}\},\{\mathrm{V}, \mathrm{W}\},\{\mathrm{X}, \mathrm{Y}\}$.

Obviously the equivalence formation through multiple reversals was evenly dissimilar within and between stimuli, although in principle within the competencies of pigeons, it is a more difficult task than when the stimuli are similar within the intended equivalence classes. This agrees with the results obtained with a separate 
so-called dissimilar group of four pigeons. They were trained and tested in the same way as the similar group during the first phase of the experiment, but dealt with the $\mathrm{A}, \mathrm{B}, \mathrm{C}, \mathrm{D}$ and $\mathrm{K}, \mathrm{L}, \mathrm{M}, \mathrm{N}$ sets composed of the dissimilar patterns shown in figure $6.2 \mathrm{~d}$, e. All, bar one, passed the tests for the $\mathrm{A} / \mathrm{K}=\mathrm{D} / \mathrm{N}$ equivalencies (mean 79 percent correct), but they all except for one failed the tests for the $C / M \equiv D / N$ equivalencies (mean 66 percent correct). When tested for command of the equivalencies $\mathrm{A} / \mathrm{K} \equiv \mathrm{C} / \mathrm{M}, \mathrm{B} / \mathrm{L} \equiv \mathrm{D} / \mathrm{N}$ derivable by transitivity, all the birds except one passed the test for the first (mean 80 percent correct), but all birds failed the test for the second equivalencies. Overall, the dissimilar group presented a pattern of results reminiscent of that of the so-called similar group of birds when these were confronted with dissimilar stimuli: the results were characterized by individualities. As detailed by Jitsumori et al. (1999), three birds of the dissimilar group ended up commanding the equivalence classes $\{\mathrm{A}, \mathrm{B}, \mathrm{C}\},\{\mathrm{K}, \mathrm{L}, \mathrm{M}\}$, and one bird commanding only the equivalence classes $\{\mathrm{A}, \mathrm{B}\},\{\mathrm{K}, \mathrm{L}\}$.

\section{Epilogue}

Jitsumori et al.'s (2000) study provides better evidence for equivalence class formation in pigeons than that produced by several earlier reversal studies. Apart from the implementation of strict reversal criteria, the pigeons may have profited from the additional training with crossed stimulus combination (the $\mathrm{A}+-\mathrm{L}-+, \mathrm{B}+-\mathrm{K}-+$ pairs, in addition to the standard $\mathrm{A}+-\mathrm{K}-+\mathrm{B}+-\mathrm{L}-+$ pairs) and the concurrent/ successive teaching of several equivalencies (the equivalencies $A / K \equiv B / L, C / M \equiv$ $\mathrm{D} / \mathrm{N}, \mathrm{A} / \mathrm{K} \equiv \mathrm{B} / \mathrm{L}, \mathrm{D} / \mathrm{N} \equiv \mathrm{C} / \mathrm{M}$ instead of only the equivalencies $\mathrm{A} / \mathrm{K} \equiv \mathrm{B} / \mathrm{L}$ ). The reversal transfer effects revealed are comparable to those obtained by Vaughan (1988). The findings substantiate Sidman's (1992) admission that multiple reversals may powerfully promote the formation of equivalence classes. He considered reflexivity, symmetry, and transitivity to be essential properties of equivalence classes. Within the multiple reversal procedure used by Jitsumori et al. (2000), the reflexivity property is not meaningful and the symmetry property is inevitably taught. But the symmetry and the transitivity property of derived equivalencies was variously tested and verified. Because the demonstrations were mostly associated with sizeable error margins, the equivalencies commanded by the pigeons are nevertheless best viewed as conforming with fuzzy rather than formal logic sets (Yager and Zadeh, 1994).

Similarity within stimuli classes and the dissimilarity between class stimulus classes appear to foster equivalence class formation. This is not surprising, as earlier pigeon studies have shown that such relationships between category stimuli facilitates the 
formation of open-ended categories that can transfer to novel exemplars (e.g., Astley and Wasserman, 1992; Jitsumori and Yoshihara, 1997; see also Mackintosh, this volume). Indeed, the successful equivalence class formation with the similar patterns might well have importantly relied on intraclass stimulus generalization and interclass discriminability of the member stimuli. However, it would be short-sighted to ascribe all the effects obtained to solely these factors. Jitsumori et al. (2000) found that the patterns that had ended up belonging to one or the other of the similar stimulus equivalence classes $\{\mathrm{A}, \mathrm{B}, \mathrm{C}, \mathrm{D}\}$ and $\{\mathrm{K}, \mathrm{L}, \mathrm{M}, \mathrm{N}\}$ were still easily discriminated by the pigeons. Also, most of the similarity group pigeons learned to include the dissimilar $\mathrm{W}$ and $\mathrm{Y}$ stimuli into the equivalence classes that they finally dominated. Most of the dissimilarity group pigeons learned to form some equivalencies with exclusively dissimilar stimuli. It must also be remembered that Vaughan's (1988) excellent equivalence formation was obtained with stimuli that were just as similar within sets as between sets. It is thus still possible that a similarity between stimuli favors equivalence formation even if no dissimilarity separates the members of the stimulus sets. This may arise because the multiple reversal procedure implements a direct discrimination between class stimuli but only promotes an indirect generalization within class stimuli.

From an ethological viewpoint, the fitness utility of the ability to class diverse stimuli, items, or events as eatable, matable, threatening, shelter-spending; homedirecting, and so forth for animals such as the pigeon is virtually beyond doubt. That natural stimuli sharing such functional properties will often, but not always, also share perceptual similarities is quite patent. That natural functional classes will sometimes vary over time so as to require continuous tracking by relearning is similarly plausible. Close to Vaughan's (1988) experiment, one may suspect that the recognition of classes of real trees that bear fruits and berries at given times of the year but not others might be directly important for frugivorous birds. Perhaps this is less true for the domestic pigeon, but the pigeon may have to solve related problems when searching for sites promising profitable foraging, auspicious nesting, or reassuring familiarity. Thus, perhaps the competence for forming such functional classes could be essential for their survival and reproduction. Undoubtedly a similar argument applies to other behaviorally advanced species. It seems probable that most mammals will show capable of full equivalence class formation as the experimental procedures are improved (rats: Nakagawa, 1992; Roberts, 1996; dolphins: Fersen and Delius, 2000; sea lions: Schusterman and Kastak, 1993; chimpanzees: Yamamoto and Asano, 1995).

Whether the experimental procedures that have been hitherto used in the attempts to demonstrate such class formation are ecologically well adjusted is not certain. The 
evolutionary circumstance that the behavioral competencies of an animal species must be tuned to the demands that the socioecological niche made on its recent ancestors suggests that it may be a worthwhile effort to adapt the laboratory procedures closer to the natural conditions. The abilities of pigeons regarding the formation of equivalence classes might be context specific and we may not yet have struck the optimal cognitive module (Shettleworth, this volume). It might be worth trying other procedures that employ more varied response requirements, more varied reinforcement consequences, and more temporally persistent schedules of reinforcement reversals than those used in the studies reviewed here. Indeed, if it was possible to devise more efficient procedures, it may be possible to extend the reversal paradigm to analogical equivalence problems encapsulated by the statement "a key is to a lock as an opener is to a can" (Premack, 1988). Suppose one would train pigeons separately on the equivalencies $\mathrm{A} / \mathrm{K} \equiv \mathrm{B} / \mathrm{L}$ using food/no-food reinforcement reversals and the equivalencies $\mathrm{C} / \mathrm{M} \equiv \mathrm{D} / \mathrm{N}$ using water/no-water reinforcement reversals. Would they then reveal reversal transfer across these pairs of equivalencies? Such a transfer in turn would argue against a narrow modular specialization of this cognitive competence.

With the possible increases in task sophistication, it will be necessary at some point to take into consideration that the avian brain size is more constrained in its progressive, anagenetic evolution than is the brain of mammals. This is because the flight capability generally imposes a limit on the body/weight independent, allometric growth of brain weight, the secondary flightlessness of some avian families notwithstanding (Jerison, 1973). If in humans variations in individual intelligence only emerge when this species is challenged with the harder items of intelligence tests, one can expect that individual pigeons may reach the limits of their intellect as they are faced with ever more difficult tasks. Moreover, pigeons are almost certainly not the cleverest avian species; the study of equivalence formation in parrots and corvids may well turn out to be more revealing (Delius et al., 2000). Indeed, some of the vocal labeling competencies exhibited by an African grey parrot may already constitute informal evidence of a remarkable capacity for equivalence formation in at least one such species (Pepperberg, 1996; see also Manabe et al., 1995, budgerigars).

These evolutionary and comparative considerations also oblige us to consider the neural mechanisms that must have evolved to enable the neurally more advanced animals, including pigeons, to learn equivalence classes. This ability must be based on secondary networks of neurons following the primary layers of the visual system engaged in extracting the basal features of visual stimuli. In mammals one would obviously consider the participation of secondary projection areas of the visual cortex. In birds, with their rather different brain make-up, the issue is less certain. But 
for what it is worth, neuroanatomists now consider larger parts of the avian forebrain (especially the structures known as ektostriatum and neostriatum) as equivalent to the mammalian neocortex, in that they probably fulfill similar information processing on the basis of an analogous, even if with a histologically less distinct structuring (Veenman, 1997). A small part of this cortical mass may even be equivalent to the prefrontal cortex of mammals (Aldavert-Vera et al., 1999), which is in turn reckoned to be the main substrate of the supramodular general intelligence in humans. Artificial neural networks, which to some extent are conceived to mimic the connectivities of cortical structures, have already shown to be amply capable of categorization and conceptualization-like feats comparable to those produced by pigeons and indeed, humans (Gluck, 1991; Roitblat and Fersen, 1992). The synaptic weights of the inputs of intermediate (or hidden) layer units or clusters of units will, with suitable simulated categorization training, come to adjust themselves so that these units or clusters will more or less indiscriminately respond to any stimulus belonging to the category they happen to represent when these stimuli are applied to the input layer. The network model may prove helpful in explaining why the equivalence effects obtained in the various reversal and matching studies have been relatively variable. All the factors that we have tentatively identified as contributing to that variability-stimulus similarities, stimulus complexities, number of stimuli, and number of reversals-are of the kind already suspected to affect concept formation in such networks.

Networks composed of at least three layers of neuronlike units are necessary to account for the formation of perceptual concepts, where the units of the intermediate, hidden layer are those principally mediating the connectivity coding of concepts (Watanabe et al., 1993). However, preliminary exploration suggests that four-layer networks might be more effective in implementing equivalencies through reversals, the additional layer enabling the formation of a distinct response/reinforcement switch circuitry. Pigeons would in any case not be short of neural layers as the first stage of their visual system alone, the tectum opticum, already contains some 15 layers (Güntürkün, 1991). Hidden units are, in any case, only effectively recruited into nodes or clusters if the training stimulus sets bear predisposing similarities/ dissimilarities, are complex enough (many stimuli, many features), and if reversals occur often enough for an concept-conform activation of these units to yield a processing advantage. Otherwise, such neural networks have a tendency to settle on a by-rote categorization, two-layer networklike manner of processing that lacks the element of concept-defining inter-stimulus associations. Networks that operate on definite instrumental conditioning principles (Siemann and Delius, 1998b) would appear to be the most promising substrates for exploring the mechanisms of equivalence class formation inasmuch as they can readily incorporate the effects of rein- 
forcement switches so central to the multiple synchronous reversal procedure that has been the main subject of this chapter.

\section{Summary}

This chapter argues that, contrary to widespread opinion, pigeons are capable of forming equivalence classes of visual stimuli. The multiple reinforcement reversal procedure originally introduced by Vaughan (1988) and recently developed by Jitsumori et al. (2000) might be more advantageous in this respect than the more popular symbolic matching-to-sample procedure advocated by Sidman (1992). This may be mainly so because the former method obviates a symmetry stage that is essential to the latter method. Although we show that physical stimulus similarities facilitate the formation of equivalence networks, it has also been demonstrated that functional similarities alone can be sufficient to yield equivalence associations. It is suggested that equivalence formation by reinforcement reversal may be within the capabilities of simple multilayer neural networks and that avians possess nervous systems that are complex enough to incorporate the requisite neuronal circuitry. From an evolutionary perspective there can be little doubt that equivalence formation capacities must be in high demand in avian natural habitats.

\section{Acknowledgments}

We thank the Deutsche Forchungsgemeinschaft and the Japanese Ministry of Education for support, Prof. I. Morgado-Bernal (Barcelona) for hospitality, and J. Grante (Exeter) for corrections.

\section{References}

Aldavert-Vera L, Costa-Miserachs D, Divac I, Delius JD (1999) Presumed "prefrontal cortex" lesions in pigeons: Effects on visual discrimination performance. Behavioral Brain Research, 102: 165-170.

Astley SL, Wasserman EA (1992) Categorical discrimination and generalization in pigeons: All negative stimuli are not created equal. Journal of Experimental Psychology: Animal Behavior Processes, 18: $193-207$. Astley SL, Wasserman EA (1998) Novelty and functional equivalence in superordinate categorization by pigeons. Animal Learning and Behavior, 26: 125-138.

Bhatt RS, Wasserman EA (1989) Secondary generalization and categorization in pigeons. Journal of the Experimental Analysis of Behavior, 52: 213-224.

Bhatt RS, Wasserman EA, Reynolds WF, Knauss KS (1988) Conceptual behavior in pigeons: Categorization of both familiar and novel examples from four classes of natural and artificial stimuli. Journal of Experimental Psychology: Animal Behavior Processes, 14: 219-234. 
D'Amato MR, Salmon DP, Loukas E, Tomie A (1985) Symmetry and transitivity of conditional relations in monkeys (Cebus apella) and pigeons (Columba livia). Journal of the Experimental Analysis of Behavior, 44: 35-47.

Delius JD (1992) Categorical discrimination of objects and pictures by pigeons. Animal Learning and Behavior, 20: 301-311.

Delius JD (1994) Comparative cognition of identity. In: International perspectives on psychological science: Leading themes (Bertelson P, Eelen P, d'Ydewalle G, ed), pp 25-40. Hillsdale, NJ, Hove, UK: Erlbaum.

Delius JD, Ameling M, Lea SEG, Staddon JER (1995) Reinforcement concordance induces and maintains stimulus associations in pigeons. Psychological Record, 45: 283-297.

Delius JD, Siemann M, Emmerton J, Xia L (2000, in press) Cognitions of birds as products of evolved brains. In: Brain, evolution and cognition (Roth G, Wullimann MF, ed), New York, Wiley.

Dougher MJ, Markham MR (1996) Stimulus classes and the untrained acquisition of stimulus functions. In: Stimulus class formation in humans and animals (Zentall TR, Smeets PM, ed), pp 137-152. Amsterdam: Elsevier.

Fersen Lv, Delius JD (1989) Long-term retention of many visual patterns by pigeons. Ethology, 82: 141155.

Fersen Lv, Delius JD (2000) Transfer of discriminative response reassignments in dolphins (Tursiops truncatus): Evidence for concept formation with auditory stimuli. Animal Cognition, in press.

Fersen Lv, Emmerton J, Delius JD (1992) Unexpected discrimination strategy used by pigeons. Behavioural Processes, 27: 139-150.

Fersen Lv, Lea SEG (1990) Category discrimination by pigeons using five polymorphous features. Journal of the Experimental Analysis of Behavior, 54: 69-84.

Fodor J (1998) When is a dog a dog? Nature, 396: 325-327.

Gluck MA (1991) Stimulus generalization and representation in adaptive network models of category learning. Psychological Science, 2: 50-55.

Güntürkün O (1991) The functional organization of the avian visual system. In: Neural and behavioural plasticity: The use of the domestic chick as a model (Andrew RJ, ed), pp 92-105. Oxford: Oxford University Press.

Herrnstein RJ (1990) Levels of stimulus control: A functional approach. Cognition, 37: 133-166.

Herrnstein RJ, Loveland DH (1964) Complex visual concept in the pigeon. Science, 146: 549-551.

Herrnstein RJ, Vaughan W; Mumford DB, Kosslyn SM (1989) Teaching pigeons an abstract relational rule: Insideness. Perception and Psychophysics, 46: 56-64.

Jerison HJ (1973) Evolution of the brain and intelligence. New York: Academic Press.

Jitsumori M (1990) No equivalences through symbolic matching in pigeons (unpublished experiment).

Jitsumori M (1993) Category discrimination of artificial polymorphous stimuli based on feature learning. Journal of Experimental Psychology: Animal Behavior Processes, 19: 244-254.

Jitsumori M, Siemann M, Lehr M, Delius JD (2000, subm.) The formation and expansion of equivalence classes in pigeons: Emergent stimulus relations through discrimination reversals.

Jitsumori M, Yoshihara M (1997) Categorical discrimination of human facial expressions by pigeons: A test of the linear feature model. Quarterly Journal of Experimental Psychology, 50B: 253-268.

Keller FS, Schoenfeld WN (1950) Principles of psychology. New York: Appleton-Century-Crofts.

Kirpatrick-Steger K, Wasserman EA (1996) The what and the where of the pigeon's processing of complex visual stimuli. Journal of Experimental Psychology: Animal Behavior Processes, 22: 60-67.

Kuno H, Kitadate T, Iwamoto T (1994) Formation of transitivity in conditional matching to sample by pigeons. Journal of the Experimental Analysis of Behavior, 62: 399-408. 
Lea SEG (1984) In what sense do pigeons learn concepts? In: Animal cognition (Roitblat HL, Bever T, Terrace HS, ed), pp 263-277. Hillsdale: Erlbaum.

Lea SEG, Ryan CME, Kirby RM (1990) Instance to category generalization following pigeon's learning of an artificial concept discrimination (unpublished manuscript).

Lipkens R, Kop PFM, Matthijs W (1988) A test of symmetry and transitivity in the conditional discrimination performances of pigeons. Journal of the Experimental Analysis of Behavior, 49: 395-409.

Lubow RE (1974) Higher-order concept formation in the pigeon. Journal of the Experimental Analysis of Behavior, 21: 475-483.

Manabe K, Kawashima T, Staddon JER (1995) Differential vocalization in budgerigars: Towards an experimental analysis of naming. Journal of the Experimental Analysis of Behavior, 63: 111-126.

Nakagawa E (1992) Effects of overtraining on reversal learning by rats in concurrent and single discriminations. Quarterly Journal of Experimental Psychology, 44B: 37-56.

Pepperberg IM (1996) Categorical class formation by an African grey parrot (Psittacus erithacus). In: Stimulus class formation in humans and animals (Zentall TR, Smeets PM, ed), pp 71-90. Amsterdam: Elsevier.

Premack D (1988) Minds with and without language. In: Thought without language (Weiskrantz L, ed), pp 46-65. Oxford: Clarendon.

Roberts WA (1996) Stimulus generalization and hierarchical structure in categorization by animals. In: Stimulus class formation in humans and animals (Zental TR, Smeets PM, ed), pp 35-54. Amsterdam: Elsevier.

Roitblat HL, Fersen LV (1992) Comparative cognition: Representation and processes in learning and memory. Annual Review of Psychology, 43: 671-710.

Schusterman RJ, Kastak D (1993) A California sea lion (Zalophus californianus) is capable of forming equivalence relations. Psychological Record, 43: 823-839.

Sidman M (1992) Equivalence relations and behavior: A research story. Boston: Authors Cooperative.

Sidman M, Rauzin R, Lazar R, Cunningham S, Tailby W, Carrigan P (1982) A search for symmetry in the conditional discrimination of rhesus monkeys, baboons and children. Journal of the Experimental Analysis of Behavior, 37: 23-34.

Sidman M, Wynne CK, Macguire RW, Barnes T (1989) Functional classes and equivalence relations. Journal of the Experimental Analysis of Behavior, 52: 261-274.

Siemann M (1998) Equivalencies by reversals in pigeons (unpublished experiment).

Siemann M, Delius JD (1998a) Induction of stimulus associations by reinforcement concordances in pigeons. In: Göttingen neurobiology report 1998 (Elsner N, Wehner R, ed), pp 447. Stuttgart: Thieme.

Siemann M, Delius JD (1998b) Algebraic learning and neural network models for transitive and nontransitive responding in humans and animals. European Journal of Cognitive Psychology, 10: 307-334.

Sloman SA, Rips LJ, ed (1998). Similarity and symbols in human thinking. Cambridge: MIT Press.

Valero-Aguayo L, Luciano-Soriano MC (1996) Relaciones de equivalencia: Un estudio de replicación del efecto de la relación simétrica sobre la transitiva. Apuntes de Psicología, 37: 25-39.

Vaughan W (1988) Formation of equivalence sets in pigeons. Journal of Experimental Psychology: Animal Behavior Processes, 14: 36-42.

Vaughan W, Greene SL (1984) Pigeons' visual memory capacity. Journal of Experimental Psychology: Animal Behavior Processes, 10: 256-271.

Veenman CL (1997) Pigeon basal ganglia: Insights into the neuroanatomy underlying telencephalic sensorimotor processes in birds. European Journal of Morphology, 35: 220-233.

Watanabe S, Lea SEG, Dittrich WH (1993) What can we learn from experiments on pigeon concept discrimination? In: Vision, brain and behavior in birds (Zeigler HP, Bishof H-J, ed), pp 351-376. Cambridge: MIT Press. 
Watanabe.S, Sakamoto J, Wakita M (1995) Pigeons' discrimination of paintings by Monet and Picasso. Journal of the Experimental Analysis of Behavior, 63: 165-174.

Wright AA, Cook RG, Rivera JJ, Sands SF, Delius JD (1988) Concept learning by pigeons: Matching-tosample with trial-unique video picture stimuli. Animal Learning and Behavior, 16: 436-444.

Xia L, Delius JD, Siemann M (1996) A multistimulus intelligence platform for pigeon conditioning. Behavior Research Methods, Instruments, and Computers, 28: 49-54.

Yager RR, Zadeh LA, ed (1994). Fuzzy sets, neural networks and soft computing. New York: Van Nostrand Reinhold.

Yamamoto J, Asano T (1995) Stimulus equivalence in a chimpanzee. Psychological Record, 45: 3-21.

Zentall TR, Steirn JN, Sherbourne LM, Urciuoli PJ (1991) Common coding in pigeons assessed through partial versus total reversals of many to one conditional and simple discriminations. Journal of Experimental Psychology: Animal Behavior Processes, 17: 194-201.

Zentall TR, Urciuoli PJ (1994) Emergent relations in the formation of stimulus classes by pigeons. Psychological Record, 43: 795-810. 